\title{
PERBAIKAN PROSES PRODUKSI PADA IKM TAHU SARI MURNI MOJOSONGO MENGGUNAKAN METODE GOOD MANUFACTURING PRACTICE (GMP) DAN WORK IMPROVEMENT IN SMALL ENTERPRISE (WISE)
}

\author{
Bambang Suhardi*, Riska Permana Sari, dan Pringgo Widyo Laksono \\ Program Studi Teknik Industri, Fakultas Teknik, Universitas Sebelas Maret \\ Email:bambangsuhardi@staff.uns.ac.id; riskaprmns@gmail.com; \\ pringgo@ft.uns.ac.id
}

Artikel masuk : 05-06-2020

\author{
Artikel direvisi : 16-06-2020 \\ *Penulis Korespondensi
}

Artikel diterima : 25-06-2020

\begin{abstract}
Abstrak - Industri Kecil dan Menengah (IKM) Tahu Sari Murni Mojosongo adalah industri tahu yang sedang berkembang di Surakarta. Proses produksi di IKM Tahu ini belum menerapkan standar Good Manufacturing Practices (GMP) yang dikeluarkan oleh BPOM (Badan Pengawas Obat dan Makanan) dan belum memperhatikan keselamatan kerja karyawan seperti dalam pedoman Work Improvement In Small Enterprise (WISE). Hal ini dibuktikan dengan hasil evaluasi kondisi aktual dengan pedoman GMP dan WISE masih banyak ditemukan penyimpangan. Penelitian ini bertujuan untuk melakukan perbaikan proses produksi di IKM yang dievaluasi menggunakan daftar periksa GMP-WISE. Daftar periksa GMP-WISE yang diperoleh memiliki 6 kriteria yaitu penyimpanan dan penanganan material/peralatan, desain tempat kerja, fasilitas kesejahteraan, organisasi pekerjaan, pengendalian proses produksi, dan program higiene dan sanitasi. Penilaian daftar periksa tersebut diperkuat dengan menggunakan metode Analytical Hierarchy Process (AHP) untuk mendapatkan keputusan terbaik dari sejumlah kriteria pada daftar periksa GMP-WISE. Hasil dari penilaian menunjukkan bahwa kriteria program higiene dan sanitasi di IKM merupakan prioritas perbaikan proses produksi. Usulan yang diberikan untuk perbaikan proses produksi di IKM adalah perancangan peraturan rutin karyawan produksi dan perancangan Standard Operating Procedure (SOP) kebersihan area kerja.
\end{abstract}

Kata kunci: Analytical Hierarchy Process; Good Manufacturing Practices; Industri Kecil dan Menengah; Work Improvement in Small Enterprise

\begin{abstract}
Small and medium industry (SMI) Tahu Sari Murni Mojosongo is a developing tofu industry in Surakarta. The production process at SMI Tahu Sari Murni Mojosongo has not implemented the Good Manufacturing Practices (GMP) standard issued by BPOM (the Food and Drug Supervisory Agency) and has not paid attention to the safety of employees' work as in the Work Improvement In Small Enterprise (WISE) guideline. This is evidenced by the results of evaluating the actual conditions with GMP and WISE guidelines still found irregularities. This study aims to improve the production process at SMI which was evaluated using the GMP-WISE checklist. The GMP-WISE checklist obtained has 6 criteria, namely material / equipment storage and handling, workplace design, welfare facilities, work organization, production process control, and hygiene and sanitation program. The checklist assessment was strengthened using the Analytical Hierarchy Process (AHP) method to get the best decision from a number of criteria on the GMP-WISE checklist. The results of the assessment indicate that the hygiene and sanitation program criteria at SMI is priority for improving the production process. The proposal given to improve the production process at SMI is the design of routine regulations for production employees and the design of the Standard Operating Procedure (SOP) for cleanliness of the work area.
\end{abstract}

Keywords: Analytical Hierarchy Process; Good Manufacturing Practices; Small and Medium Industry; Work Improvement in Small Enterprise 


\section{PENDAHULUAN}

Industri tahu di Kota Surakarta memiliki jumlah unit usaha terbesar ketiga setelah industri tempe serta industri mebel. Jumlah industri tahu di kota Surakarta adalah sebanyak 99 unit (Putri, 2010). Permintaan tahu di Kota Surakarta cukup besar yang dilihat dari kebutuhan kedelai bagi industri. Menurut Dinas Perindustrian dan Perdagangan Surakarta dalam (Putri, 2010), kebutuhan kedelai untuk produksi tahu pada industri tahu daerah Jebres, Surakarta sebesar $2.846 .660 \mathrm{~kg} / \mathrm{tahun}$.

Salah satu industri tahu yang sedang berkembang di Kota Surakarta adalah IKM Tahu Sari Murni yang terletak di Desa Krajan RT. 03/RW. 03 Mojosongo, Kecamatan Jebres, Kota Surakarta. Proses pembuatan tahu tersebut terdiri dari beberapa tahap yaitu perendaman, pencucian, penggilingan, perebusan, penyaringan, penggumpalan, pencetakan, dan pemotongan. Proses produksi tahu di IKM Tahu Sari Murni masih dilakukan secara manual dengan menggunakan peralatan yang sederhana dan kurang memperhatikan kebersihan proses produksinya. Hal tersebut terlihat dari hasil pengamatan yang dilakukan yaitu karyawan tidak mengenakan penutup kepala, sarung tangan dan baju saat proses produksi tahu. Risiko yang dapat ditimbulkan yaitu terjadinya kontaminasi pada produk tahu yang dihasilkan karena tercampur dengan rambut, keringat, dan kotoran lainnya yang berasal dari pekerja ke dalam sari kedelai yang sedang direbus.

Kondisi lainnya yaitu pada dinding, pintu, ventilasi dan langit-langit bangunan produksi juga terdapat debu dan sarang serangga yang dapat jatuh ke dalam sari kedelai yang sedang dimasak atau pada produk akhir tahu. Risiko bahaya yang mungkin dapat terjadi yaitu kontaminasi produk akhir tahu yang dihasilkan karena tercampur dengan debu atau kotoran lainnya. Hal tersebut dapat terjadi karena keadaan ruang produksi yang sifatnya terbuka sehingga debu dan kotoran lainnya mudah masuk kedalam ruang produksi.

Hasil dari uraian permasalahan tersebut, menunjukkan bahwa proses produksi IKM Tahu Sari Murni belum sesuai dengan pedoman GMP sebagai syarat utama dalam proses produksi makanan di Indonesia (BPOM, 2012). Selain itu, IKM juga belum menerapkan sistem kesehatan dan keselamatan kerja yang baik (ILO, 2015) yaitu karyawan harus mengenakan pakaian kerja/celemek lengkap dengan penutup kepala, sarung tangan, masker dan sepatu kerja saat proses produksi. Beberapa peneliti menyatakan bahwa faktor yang menyebabkan terjadinya keracunan makanan, adalah hygiene perorangan yang buruk, cara penanganan makanan yang tidak sehat, dan perlengkapan pengolahan makanan yang tidak bersih (Fatmawati, Rosidi \& Handarsari, 2013; Ningsih, 2014). Selain itu Sari (2016) menyatakan keamanan pangan juga ditentukan dari perilaku para pekerja industri makanan, seperti perilaku pemakaian masker, sarung tangan saat bekerja.

Oleh karena itu, perlu dilakukan perbaikan sistem kerja produksi tahu di IKM Tahu Sari Murni dengan menggunakan metode GMP dan Work Improvement in Small Enterprises (WISE). Penerapan GMP pada industri pangan bisa meningkatkan kualitas dan daya saing dari produk pangan (Wardanu \& Anhar, 2016; Hanidah, Mulyono, Andoyo, Mardawati \& Huda, 2018). Beberapa penelitian terdahulu telah menggunakan GMP dan WISE dengan tujuan untuk mengidentifikasi kondisi keamanan pangan pada industri rumah tangga serta keamanan pada pekerja (Suhardi, Kadita, \& Laksono, 2018; Suhardi, Putri, \& Astuti, 2019; Suhardi, Wardani, \& Jauhari, 2019). Untuk mendapatkan keputusan terbaik dari sejumlah kriteria yang ada dalam GMP dan WISE, maka diperkuat menggunakan metode AHP. Seperti penelitian (Damarasri, Partiwi, \& Gunawan, 2013), yang menggunakan metode AHP untuk pemilihan prioritas kriteria dalam perbaikan sistem kerja di UKM tempe tenggilis Mejoyo Surabaya. Selain itu (Suhardi, Kadita \& Laksono, 2018) juga menggunakan AHP untuk melakukan pembobotan kriteria dan subkriteria daftar periksa GMP-WISE. Keseluruhan perbaikan proses produksi tersebut bertujuan untuk menghasilkan produk yang aman dikonsumsi dan mengurangi kecelakaan kerja.

\section{METODE PENELITIAN \\ Tahap Pengumpulan Data}

Pengambilan data primer dilakukan dengan cara melakukan observasi di tempat produksi dan wawancara dengan pemilik IKM Tahu Sari Murni. Data primer yang diambil yaitu keseluruhan proses produksi IKM Tahu Sari Murni yang meliputi layout IKM Tahu Sari Murni, proses produksi pembuatan tahu, kondisi lingkungan tempat kerja, aktivitas pekerja selama proses produksi, kebersihan peralatan dan karyawan produksi, dan data tentang ketersediaan APD untuk pekerja.

Sedangkan data sekunder adalah data atau informasi yang telah tersedia oleh pihak perusahaan atau pihak lain yang dianggap berkompeten. Data sekunder yang diambil adalah profil perusahaan, data tentang sertifikasi P-IRT 
dan data kecelakaan kerja selama satu tahun terakhir.

\section{Tahap Pengolahan Data}

Metode yang digunakan pada penelitian ini adalah: GMP, WISE, dan AHP. Tahapan dalam pengolahan data sebagai berikut:

1. Evaluasi kondisi saat ini dengan GMP dan WISE

GMP yang digunakan untuk evaluasi kondisi saat ini terdiri dari 14 kriteria yaitu: lokasi dan lingkungan produksi, bangunan dan fasilitas, peralatan produksi, suplai air atau sarana penyediaan air, fasilitas dan kegiatan higiene dan sanitasi, kesehatan dan higiene karyawan, pemeliharaan dan program higiene dan sanitasi, penyimpanan, pengendalian proses, pelabelan pangan, pengawasan oleh penanggung jawab, penarikan produk, pencatatan dan dokumentasi, dan pelatihan karyawan. WISE terdiri dari 8 kriteria yaitu: penyimpanan dan penanganan material, desain tempat kerja, keamanan mesin produktif, lingkungan fisik, proteksi bahaya listrik, penanggulangan bahaya kebakaran, fasilitas kesejahteraan, dan organisasi pekerjaan. Pada tahap ini dilakukan evaluasi kondisi saat ini di IKM berdasarkan kriteria GMP dan WISE. Evaluasi dilakukan dengan memberikan penilaian pada kriteria tersebut. Suatu kondisi dikatakan prioritas apabila kondisi di IKM saat ini membutuhkan dan tidak sesuai dengan pedoman GMP dan WISE. Kondisi dikatakan tidak prioritas apabila kondisi di IKM tidak membutuhkan dan sesuai dengan pedoman GMP dan WISE.

\section{Penyusunan Daftar Periksa GMP-WISE}

Penyusunan daftar periksa GMP-WISE didapatkan dari hasil evaluasi kondisi saat ini dengan kriteria dan subkriteria pada pedoman GMP dan WISE yang menjadi prioritas perbaikan. Sedangkan kriteria dan subkriteria yang tidak prioritas tersebut akan dieliminasi dan tidak digunakan dalam penyusunan daftar periksa GMP-WISE.

\section{Pembobotan Kriteria Penilaian}

Penilaian kondisi kerja IKM dari daftar periksa GMP-WISE kemudian diolah dengan kuesioner AHP. Kuesioner AHP diisi oleh responden yang expert di bidangnya. Hasil kuesioner AHP yang berupa urutan kriteria yang harus diperbaiki menjadi dasar untuk perbaikan proses produksi. Perbaikan proses produksi dilakukan berdasarkan hasil pembobotan kriteria pada daftar periksa GMP-WISE.

\section{HASIL DAN PEMBAHASAN \\ Evaluasi Kondisi Saat Ini}

Proses evaluasi kondisi saat ini di IKM Tahu Sari Murni dilakukan berdasarkan kriteria GMP dan WISE. Terdapat 14 kriteria dalam GMP dan 8 kriteria dalam pedoman WISE. Penilaian dilakukan untuk mengetahui kesesuaian kondisi saat ini di IKM dengan pedoman yang berlaku. Contoh penilaian kondisi saat ini dengan GMP dapat dilihat pada Tabel 1 dan contoh penilaian kondisi saat ini dengan WISE ditunjukkan pada Tabel 2.

Tabel 1. Contoh Penilaian Kondisi Saat ini dengan GMP

\begin{tabular}{|c|c|c|c|c|}
\hline No & $\begin{array}{l}\text { Kriteria } \\
\text { GMP }\end{array}$ & $\begin{array}{c}\text { Subkriteria } \\
\text { GMP }\end{array}$ & $\begin{array}{c}\text { Kondisi Saat } \\
\text { Ini }\end{array}$ & Penilaian \\
\hline \multirow{5}{*}{1} & \multirow{5}{*}{$\begin{array}{l}\text { Lingkungan } \\
\text { produksi }\end{array}$} & $\begin{array}{l}\text { Bebas } \\
\text { pencemaran, } \\
\text { semak } \\
\text { belukar dan } \\
\text { genangan air }\end{array}$ & $\begin{array}{l}\text { Lingkungan } \\
\text { produksi berada } \\
\text { di tempat yang } \\
\text { bebas dari } \\
\text { semak belukar } \\
\text { dan genangan } \\
\text { air tetapi dekat } \\
\text { dengan sungai } \\
\text { sebagai tempat } \\
\text { pembuangan } \\
\text { limbah cair }\end{array}$ & $\begin{array}{l}\text { Tidak } \\
\text { Prioritas }\end{array}$ \\
\hline & & $\begin{array}{l}\text { Bebas dari } \\
\text { sarang hama, } \\
\text { khususnya } \\
\text { serangga dan } \\
\text { binatang } \\
\text { pengerat }\end{array}$ & $\begin{array}{l}\text { Tempat } \\
\text { produksi } \\
\text { terdapat } \\
\text { sarang } \\
\text { serangga di } \\
\text { langit-langit } \\
\text { dan sudut- } \\
\text { sudut dinding }\end{array}$ & Prioritas \\
\hline & & $\begin{array}{l}\text { Tidak berada } \\
\text { di daerah } \\
\text { sekitar } \\
\text { tempat } \\
\text { pembuangan } \\
\text { sampah baik } \\
\text { sampah } \\
\text { padat } \\
\text { maupun } \\
\text { sampah cair }\end{array}$ & $\begin{array}{l}\text { Lingkungan } \\
\text { produksi tidak } \\
\text { berada di } \\
\text { daerah } \\
\text { sekitar } \\
\text { tempat } \\
\text { pembuangan } \\
\text { sampah } \\
\text { tetapi berada } \\
\text { di dekat } \\
\text { sungai } \\
\text { sebagai } \\
\text { tempat } \\
\text { pembuangan } \\
\text { limbah cair }\end{array}$ & $\begin{array}{l}\text { Tidak } \\
\text { Prioritas }\end{array}$ \\
\hline & & $\begin{array}{l}\text { IRT tidak } \\
\text { berada di } \\
\text { daerah } \\
\text { pemukiman } \\
\text { penduduk } \\
\text { yang kumuh }\end{array}$ & $\begin{array}{l}\text { IRT berada di } \\
\text { daerah } \\
\text { pemukiman } \\
\text { penduduk } \\
\text { yang bersih }\end{array}$ & $\begin{array}{l}\text { Tidak } \\
\text { Prioritas }\end{array}$ \\
\hline & & $\begin{array}{l}\text { Sampah } \\
\text { harus } \\
\text { dibuang dan } \\
\text { tidak } \\
\text { menumpuk }\end{array}$ & $\begin{array}{l}\text { Sampah di } \\
\text { lingkungan } \\
\text { produksi } \\
\text { selalu } \\
\text { dibuang di } \\
\text { tempat } \\
\text { pembuangan } \\
\text { sampah. Hal } \\
\text { ini dilakukan } \\
\text { agar produk } \\
\text { pangan yang } \\
\text { diproduksi } \\
\text { tidak } \\
\text { tercemar } \\
\text { dengan } \\
\text { kotoran dari } \\
\text { sampah }\end{array}$ & $\begin{array}{l}\text { Tidak } \\
\text { Prioritas }\end{array}$ \\
\hline
\end{tabular}


Tabel 2. Contoh Penilaian Kondisi Saat ini dengan WISE

\begin{tabular}{|c|c|c|c|c|}
\hline No & Kriteria & $\begin{array}{l}\text { Pedoman } \\
\text { WISE }\end{array}$ & $\begin{array}{c}\text { Kondisi Saat } \\
\text { Ini }\end{array}$ & Penilaian \\
\hline \multirow[t]{3}{*}{3} & \multirow[t]{3}{*}{$\begin{array}{l}\text { Keamanan } \\
\text { mesin } \\
\text { produktif }\end{array}$} & $\begin{array}{l}\text { Menggunakan } \\
\text { perangkat } \\
\text { yang aman } \\
\text { untuk } \\
\text { memasukkan } \\
\text { dan } \\
\text { mengeluarkan } \\
\text { material dari } \\
\text { mesin agar } \\
\text { tangan } \\
\text { menjauh dari } \\
\text { bagian-bagian } \\
\text { berbahaya dari } \\
\text { mesin }\end{array}$ & $\begin{array}{l}\text { Biasanya } \\
\text { karyawan } \\
\text { menggunakan } \\
\text { alat bantu } \\
\text { kayu untuk } \\
\text { mengeluarkan } \\
\text { material dari } \\
\text { mesin }\end{array}$ & $\begin{array}{l}\text { Tidak } \\
\text { Prioritas }\end{array}$ \\
\hline & & $\begin{array}{l}\text { Menggunakan } \\
\text { pelindung dan } \\
\text { penghalang } \\
\text { yang } \\
\text { permanen } \\
\text { untuk } \\
\text { mencegah } \\
\text { kontak } \\
\text { langsung } \\
\text { dengan bagian } \\
\text { mesin yang } \\
\text { bergerak }\end{array}$ & $\begin{array}{l}\text { Pada IKM } \\
\text { hanya } \\
\text { menggunakan } \\
\text { satu alat } \\
\text { bantu yaitu } \\
\text { mesin giling. } \\
\text { Pada bagian } \\
\text { mesin yang } \\
\text { bergerak tidak } \\
\text { diberi } \\
\text { pelindung } \\
\text { atau } \\
\text { penghalang }\end{array}$ & Prioritas \\
\hline & & $\begin{array}{l}\text { Memeriksa, } \\
\text { membersihkan } \\
\text { dan } \\
\text { memelihara } \\
\text { mesin-mesin } \\
\text { secara teratur }\end{array}$ & $\begin{array}{l}\text { Pemeriksaan, } \\
\text { pembersihan } \\
\text { dan } \\
\text { pemeliharaan } \\
\text { mesin giling } \\
\text { dilakukan jika } \\
\text { terjadi } \\
\text { kerusakan. }\end{array}$ & Prioritas \\
\hline
\end{tabular}

Penilaian kondisi saat ini di IKM Tahu Sari Murni dilakukan pada semua kriteria berdasarkan pedoman GMP dan WISE. Penilaian tersebut dilakukan dengan menilai kriteria yang dinilai menjadi prioritas dan tidak prioritas dalam perbaikan proses produksi. Berdasarkan hasil evaluasi diperoleh hasil berdasarkan pedoman GMP terdapat 9 kriteria masuk dalam kategori prioritas dan 5 kriteria masuk dalam kategori tidak prioritas. Kriteria yang termasuk kategori prioritas adalah: bangunan dan fasilitas, peralatan produksi, suplai air, fasilitas dan kegiatan higiene dan sanitasi, kesehatan dan higiene karyawan, pengendalian proses, pelabelan pangan, pengawasan oleh penanggung jawab, dan pelatihan karyawan. Sedangkan kriteria yang tidak prioritas yaitu lingkungan produksi, pemeliharaan dan program higiene dan sanitasi, penyimpanan, penarikan produk, pencatatan dan dokumentasi bangunan dan fasilitas industri rumah tangga (IRT).

Berdasarkan pedoman WISE terdapat 7 kriteria dalam kategori prioritas dan 1 kriteria dalam kategori tidak prioritas. Kriteria yang menjadi prioritas perbaikan yaitu penyimpanan dan penanganan material, keamanan mesin produktif, lingkungan fisik, proteksi bahaya listrik, penanggulangan bahaya kebakaran, fasilitas kesejahteraan, dan organisasi pekerjaan. Kriteria yang tidak prioritas adalah desain tempat kerja.

\section{Penyusunan Daftar Periksa GMP-WISE}

Kriteria dan subkriteria yang tidak prioritas baik pada GMP maupun WISE akan dieliminasi dan tidak digunakan dalam penyusunan daftar periksa GMP-WISE. Kriteria yang termasuk kategori prioritas pada GMP (9 kriteria) dan WISE (7 kriteria) bisa dikelompokan menjadi 6 kriteria. Karena kriteria pada GMP dan WISE ada beberapa yang memiliki kesamaan. Dasar pengelompokan kriteria ini juga mengacu pada penelitian (Damarasri, Partiwi, \& Gunawan, 2013) serta pedoman GMP dan WISE.

Daftar periksa GMP-WISE yang terdiri 6 kriteria ini digunakan untuk menentukan prioritas perbaikan proses produksi yang akan dilakukan di IKM Tahu Sari Murni. Daftar periksa GMP-WISE yang baru terdiri dari 6 kriteria dan 26 subkriteria. Daftar periksa GMP-WISE dapat dilihat pada Tabel 3.

Tabel 3. Daftar Periksa GMP-WISE

\begin{tabular}{|c|c|c|}
\hline No & Kriteria & Sub-Kriteria \\
\hline 1 & $\begin{array}{l}\text { Penyimpanan dan } \\
\text { penanganan } \\
\text { material/peralatan }\end{array}$ & $\begin{array}{l}\text { Kebersihan penyimpanan bahan } \\
\text { baku } \\
\text { Peralatan perpindahan dan } \\
\text { penyimpanan material } \\
\text { Pemeriksaan peralatan produksi } \\
\text { Kebersihan peralatan produksi }\end{array}$ \\
\hline 2 & Desain tempat kerja & $\begin{array}{l}\text { Ruang produksi yang luas dan } \\
\text { sesuai urutan } \\
\text { Kondisi lantai, dinding, ventilasi dan } \\
\text { langit-langit } \\
\text { Lokasi produksi } \\
\text { Ketersediaan air yang cukup }\end{array}$ \\
\hline 3 & $\begin{array}{l}\text { Fasilitas } \\
\text { kesejahteraan }\end{array}$ & $\begin{array}{l}\text { Fasilitas minum dan makan } \\
\text { Sarana cuci tangan } \\
\text { Sarana toilet/jamban } \\
\text { Sarana pembersihan peralatan dan } \\
\text { perlengkapan } \\
\text { Perlengkapan APD } \\
\text { Peralatan P3K }\end{array}$ \\
\hline 4 & $\begin{array}{l}\text { Organisasi } \\
\text { pekerjaan }\end{array}$ & $\begin{array}{l}\text { Pelatihan karyawan } \\
\text { Pengawasan proses produksi } \\
\text { Dokumentasi produksi } \\
\text { Penarikan produk }\end{array}$ \\
\hline 5 & $\begin{array}{l}\text { Pengendalian } \\
\text { proses produksi }\end{array}$ & $\begin{array}{l}\text { Catatan kerusakan bahan baku } \\
\text { Bagan alir produksi } \\
\text { Kemasan produk } \\
\text { Potensi bahaya listrik } \\
\text { Bahaya kebakaran }\end{array}$ \\
\hline 6 & $\begin{array}{l}\text { Program higiene dan } \\
\text { sanitasi }\end{array}$ & $\begin{array}{l}\text { Program higiene karyawan } \\
\text { Program higiene tempat kerja } \\
\text { Antisipasi zat berbahaya }\end{array}$ \\
\hline
\end{tabular}

\section{Pembobotan Daftar Periksa GMP-WISE}

Tahap awal yang akan dilakukan yaitu melakukan penyusunan struktur hierarki. Tujuan dilakukannya tahap ini adalah untuk menyederhanakan permasalahan yang ada. Struktur hierarki penentuan kriteria dan subkriteria dapat dilihat pada Gambar 1. 


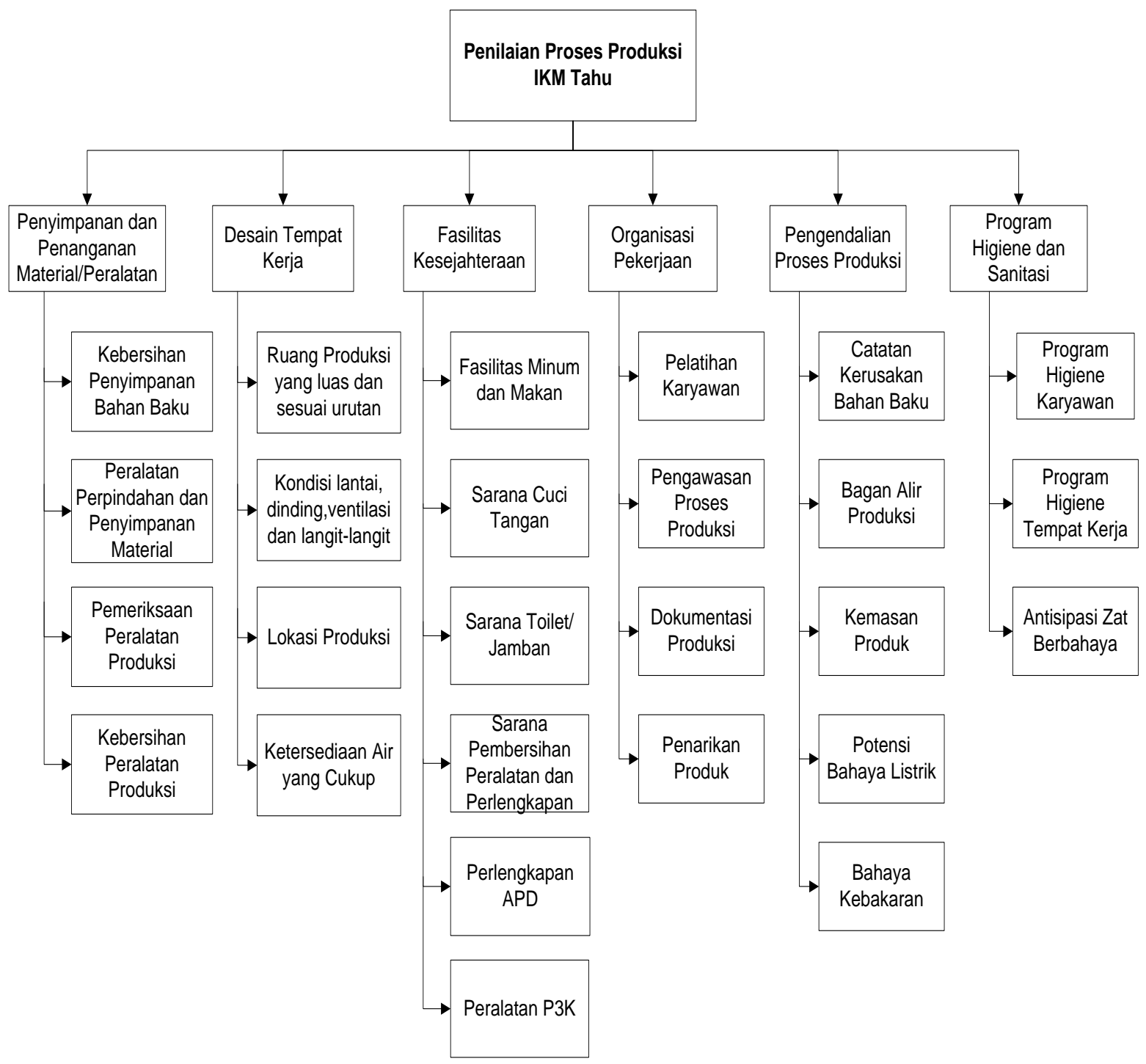

Gambar 1. Struktur Hierarki Penentuan Kriteria dan Subkriteria di IKM Tahu Sari Murni

Bobot prioritas kriteria dan subkriteria hasil penilaian proses produksi di IKM Tahu Sari Murni ditunjukkan pada Tabel 4. Kriteria penyimpanan dan penanganan material/peralatan mempunyai bobot sebesar $19 \%$, desain tempat kerja sebesar $13 \%$, fasilitas kesejahteraan sebesar $16 \%$, organisasi pekerjaan sebesar $15 \%$, pengendalian proses produksi sebesar $15 \%$, dan program higiene dan sanitasi sebesar $22 \%$.

Proses perbaikan akan dilakukan secara bertahap. Proses perbaikan yang dilakukan yaitu yang memiliki prosentase tertinggi berdasarkan kriteria yang terdapat dalam daftar periksa CPPBWISE. Prosentase prioritas perbaikan tertinggi terdapat pada kriteria program higiene dan sanitasi. Pada kriteria ini memiliki 3 subkriteria di dalamnya yang juga dilakukan penilaian prioritas perbaikan. Hasil prosentase dari ketiga subkriteria tersebut yaitu program higiene karyawan sebesar
$41 \%$, program higiene tempat kerja sebesar $33 \%$, dan antisipasi zat berbahaya sebesar $26 \%$.

\section{Usulan Perbaikan Proses Produksi IKM Tahu Sari Murni}

Berdasarkan hasil penilaian proses produksi IKM Tahu Sari Murni, maka prioritas perbaikan dilakukan pada kriteria yang memiliki nilai prosentase tertinggi yaitu program higiene dan sanitasi. Kriteria program higiene dan sanitasi memiliki 3 sub kriteria untuk perbaikannya yaitu program higiene karyawan, program higiene tempat kerja dan antisipasi zat berbahaya. Ketiga subkriteria tersebut menjadi prioritas perbaikan karena terdapat banyak penyimpangan di IKM Tahu Sari Murni. Penyimpangan yang terjadi berdasarkan ketiga subkriteria tersebut dapat dilihat pada Tabel 5. 
Tabel 4. Rekapitulasi Bobot Prioritas Kriteria dan Subkriteria Penilaian Proses Produksi IKM Tahu Sari Murni

\begin{tabular}{|c|c|c|}
\hline $\begin{array}{c}\text { Kriteria dan Subkriteria Sistem Kerja IKM Tahu Sari } \\
\text { Murni }\end{array}$ & \multicolumn{2}{|c|}{ Bobot } \\
\hline $\begin{array}{l}\text { 1. Penyimpanan dan Penanganan Material/Peralatan } \\
\text { a. Kebersihan penyimpanan bahan baku } \\
\text { b. Peralatan perpindahan dan penyimpanan material } \\
\text { c. Pemeriksaan peralatan produksi } \\
\text { d. Kebersihan peralatan produksi }\end{array}$ & $\begin{array}{c}26 \% \\
9 \% \\
22 \% \\
43 \%\end{array}$ & $19 \%$ \\
\hline $\begin{array}{l}\text { 2. Desain Tempat Kerja } \\
\text { a. Ruang produksi yang luas dan sesuai urutan } \\
\text { b. Kondisi lantai, dinding, ventilasi dan langit-langit } \\
\text { c. Lokasi produksi } \\
\text { d. Ketersediaan air yang cukup } \\
\end{array}$ & $\begin{array}{l}25 \% \\
30 \% \\
25 \% \\
20 \% \\
\end{array}$ & $13 \%$ \\
\hline $\begin{array}{l}\text { 3. Fasilitas Kesejahteraan } \\
\text { a. Fasilitas umum dan makan } \\
\text { b. Sarana cuci tangan } \\
\text { c. Sarana toilet/jamban } \\
\text { d. Sarana pembersihan peralatan dan perlengkapan } \\
\text { e. Perlengkapan alat pelindung diri (APD) } \\
\text { f. Peralatan P3K }\end{array}$ & $\begin{array}{l}17 \% \\
12 \% \\
16 \% \\
20 \% \\
18 \% \\
17 \%\end{array}$ & $16 \%$ \\
\hline $\begin{array}{l}\text { 4. } \text { Organisasi Pekerjaan } \\
\text { a. Pelatihan karyawan } \\
\text { b. Pengawasan proses produksi } \\
\text { c. Dokumentasi produksi } \\
\text { d. Penarikan produk }\end{array}$ & $\begin{array}{l}21 \% \\
25 \% \\
25 \% \\
30 \%\end{array}$ & $15 \%$ \\
\hline $\begin{array}{l}\text { 5. } \\
\text { a. } \\
\text { bengendalian Proses Produksi } \\
\text { b. Bagan alir produksi } \\
\text { c. Kemasan produk } \\
\text { d. Potensi bahaya listrik } \\
\text { e. } \\
\text { Bahaya kebakaran }\end{array}$ & $\begin{array}{l}20 \% \\
16 \% \\
25 \% \\
20 \% \\
20 \%\end{array}$ & $15 \%$ \\
\hline $\begin{array}{l}\text { 6. } \\
\text { a. Program Higiene dan Sanitasi } \\
\text { b. Program higiene tempat kerja } \\
\text { c. Antisipasi zat berbahaya } \\
\end{array}$ & $\begin{array}{l}41 \% \\
33 \% \\
26 \% \\
\end{array}$ & $22 \%$ \\
\hline$y_{2}$ & & $100 \%$ \\
\hline
\end{tabular}

Tabel 5. Penyimpangan yang Menjadi Prioritas Perbaikan Proses Produksi

\begin{tabular}{|c|c|c|}
\hline \multicolumn{3}{|c|}{ Program Higiene Karyawan } \\
\hline No & Penyimpangan & Gambal \\
\hline 1. & $\begin{array}{l}\text { Pekerja kurang menjaga kebersihan badannya. Terdapat pekerja yang tidak } \\
\text { mencuci tangan ketika akan memulai kegiatan mengolah pangan dan } \\
\text { sesudah menangani bahan/alat yang kotor. Akibat yang dapat ditimbulkan } \\
\text { yaitu menempelnya debu atau kotoran lainnya pada makanan yang sedang } \\
\text { diolah yang berasal dari tangan pekerja. }\end{array}$ & \\
\hline
\end{tabular}


Tabel 5. Penyimpangan yang Menjadi Prioritas Perbaikan Proses Produksi (Lanjutan)

\begin{tabular}{ll}
\hline No & \multicolumn{1}{c}{ Program Higiene Karyawan } \\
\hline 2. & \multicolumn{1}{c}{ Penyimpangan } \\
& $\begin{array}{l}\text { Pekerja tidak mengenakan pakaian kerja saat proses produksi. Selain itu, } \\
\text { masker, dan sarung tangan. APD tersebut sudah disediakan oleh pemilik IKM, }\end{array}$ \\
& namun pekerja tidak bersedia menggunakannya. Akibat yang dapat \\
& $\begin{array}{l}\text { ditimbulkan yaitu keringat yang keluar dari tubuh pekerja dapat menetes pada } \\
\text { produk yang sedang diolah. Selain itu terjadi kecelakaan kerja saat proses } \\
\text { produksi berupa tangan dan perut tersiram air panas. }\end{array}$
\end{tabular}

3. Pada saat proses produksi pangan terdapat pekerja produksi yang makan, minum dan merokok di area tempat produksi. Kondisi ini dilakukan setiap hari oleh pekerja. Akibat yang dapat ditimbulkan yaitu jatuhnya remah-remah makanan dan abu rokok ke dalam produk yang sedang diolah. Hal ini dapat menyebabkan produk pangan yang dihasilkan terkontaminasi.

4. Terdapat pekerja yang mengenakan gelang pada saat proses produksi pangan. Pekerja perempuan mengenakan perhiasan gelang, sedangkan pekerja laki-laki mengenakan gelang karet di tangannya. Akibat yang dapat ditimbulkan yaitu terjadinya kontaminasi pada pangan yang sedang diolah karena jatuhnya kotoran atau serpihan logam yang terdapat pada gelang.

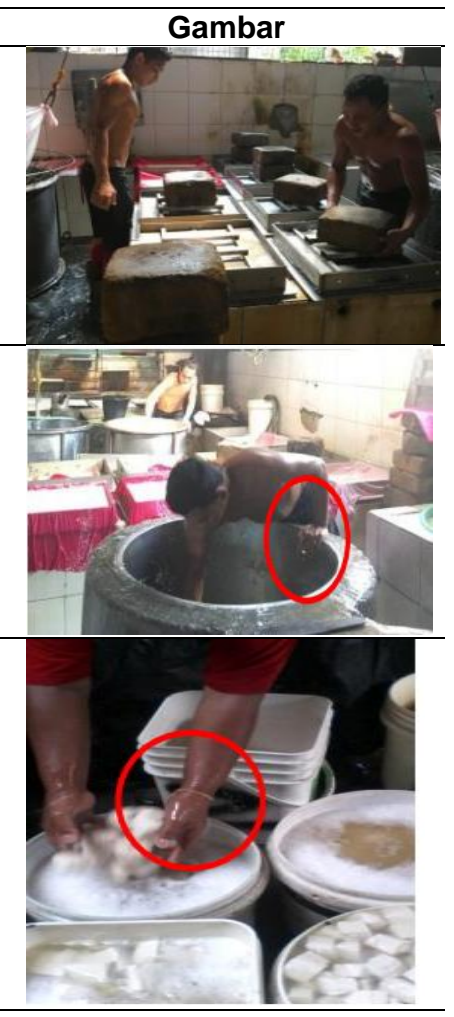

Program Higiene Area Tempat Kerja

\begin{tabular}{cc}
\hline No & Penyimpangan \\
\hline 1. & Terdapat sarang serangga, debu dan kotoran lainnya di dinding, langit-langit, \\
& pintu, dan jendela tempat produksi, sehingga dapat menyebabkan debu atau \\
kotoran lainnya jatuh pada produk pangan yang sedang diproduksi
\end{tabular}

2. Lantai bangunan produksi selalu dalam keadaan basah dan terdapat lendir sari tahu. Akibat yang dapat ditimbulkan yaitu lantai menjadi licin ketika dilewati, sehingga menyebabkan kecelakaan kerja yaitu pekerja terpeleset

3. Tempat cuci tangan yang terdapat pada ruang produksi kurang terawat dengan baik. Akibat yang dapat ditimbulkan yaitu pekerja tidak suka menggunakan fasilitas tersebut karena kurang terawat. Pekerja memilih cuci tangan menggunakan air yang digunakan untuk mengolah produk, sehingga air tersebut dapat terkontaminasi dengan kotoran yang terdapat pada tangan pekerja.

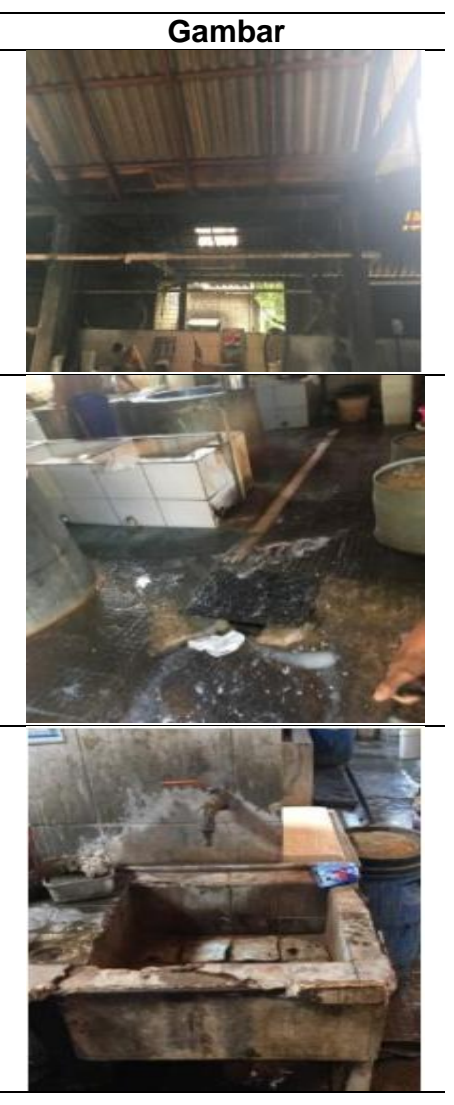


Hasil penelitian ini memperkuat penelitian sebelumnya, dimana kualitas makanan ditentukan oleh higiene \& sanitasi karyawan serta higiene \& sanitasi area dapur (Setyawanti \& Andayani, 2015; Yulianto \& Nurcholis, 2015; Firdausi, Rahardjo \& Hanani D, 2017). Keseluruhan usulan perbaikan yang dilakukan berdasarkan permasalahan yang terjadi saat ini di IKM Tahu Sari Murni Mojosongo yaitu penyusunan peraturan rutin karyawan produksi dan penyusunan SOP kebersihan di area kerja. Usulan perbaikan dengan membuat SOP ini sesuai dengan hasil penelitian (Fatmawati, Rosidi \& Handarsari, 2013), dimana untuk menerapkan higiene pada pekerja perlu dibuat SOP. Peraturan Rutin Karyawan Produksi dapat dilihat pada Tabel 6. Sedangkan SOP dapat dilihat pada Tabel 7.

Peraturan rutin karyawan bagian produksi untuk menggunakan pakaian kerja seperti celemek, penutup kepala, sarung tangan, masker pada saat bekerja mengacu pada peraturan ILO (2015) dan sesuai dengan hasil penelitian (Setyawanti \& Andayani, 2015). Peraturan mengenai panjang kuku karyawan bagian produksi tidak boleh lebih dari $1 \mathrm{~mm}$ mengacu pada penelitian (Firdausi, Rahardjo \& Hanani D, 2017).

Tabel 6. Peraturan Rutin Karyawan Produksi

\section{PERATURAN RUTIN KARYAWAN PRODUKSI IKM TAHU SARI MURNI}

Tujuan dibentuknya peraturan ini adalah mengurangi cemaran pada pangan yang disebabkan oleh kesehatan, higiene perorangan dan tingkah laku saat bekerja di ruang produksi.

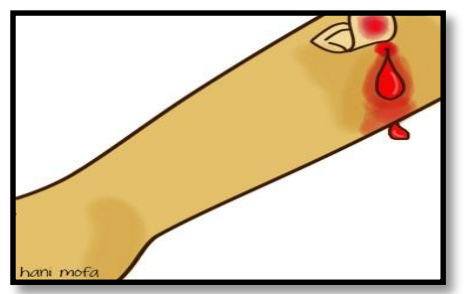

Sumber : http://www.majalahsehat.com Karyawan yang mengidap luka terbuka tidak diperbolehkan bekerja
Sumber :

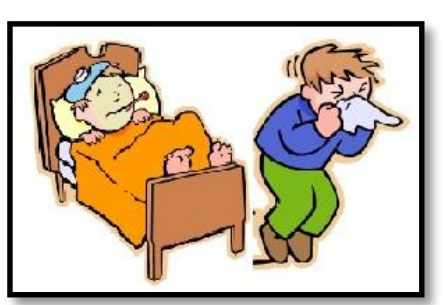

https://selfyparkit.wordpress.com

Karyawan yang sedang sakit tidak diperbolehkan bekerja

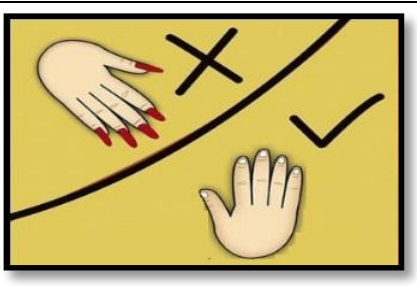

Sumber :http://www.vedcmalang.com Panjang kuku karyawan tidak boleh lebih dari $1 \mathrm{~mm}$.

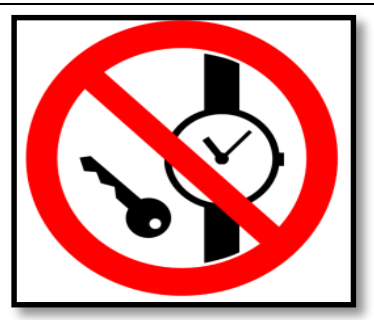

Sumber : http://www.vedcmalang.com Karyawan tidak diperbolehkan memakai perhiasan/jam tangan saat bekerja

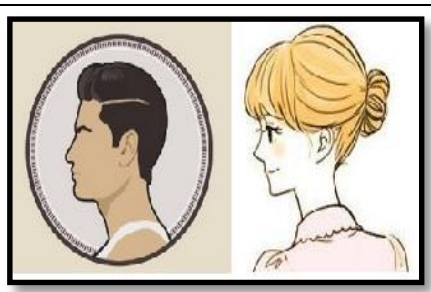

Sumber :http://dindun45.blogspot.co.id Karywan laki-laki harus berambut pendek dan perempuan di kuncir.

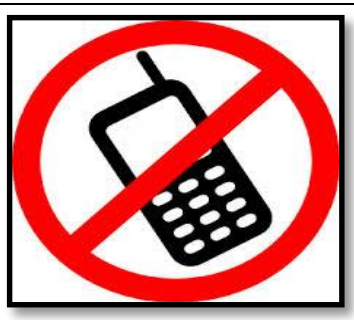

Sumber : http://www.vedcmalang.com

Karyawan tidak diperkenankan membawa alat elektronik saat proses produksi 
Tabel 6. Peraturan Rutin Karyawan Produksi (Lanjutan)

\section{PERATURAN RUTIN KARYAWAN PRODUKSI IKM TAHU SARI MURNI}

Tujuan dibentuknya peraturan ini adalah mengurangi cemaran pada pangan yang disebabkan oleh kesehatan, higiene perorangan dan tingkah laku saat bekerja di ruang produksi.

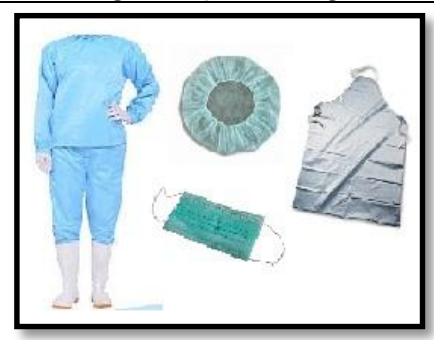

Sumber : http://www.vedcmalang.com Karyawan wajib memakai pakaian kerja, celemek, sepatu safety, penutup kepala, sarung tangan, masker saat bekerja

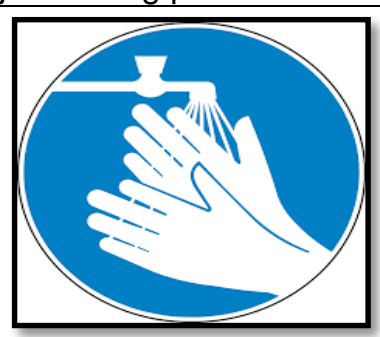

Sumber : http://www.vedcmalang.com Karyawan wajib mencuci tangan dengan sabun sebelum memulai atau sesudah proses produksi

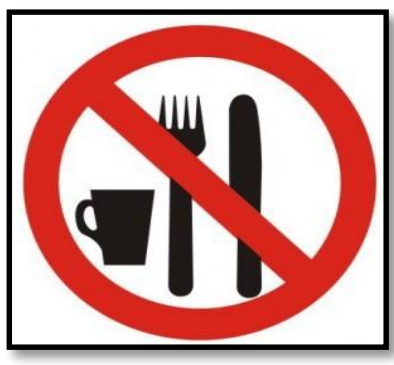

Sumber : http://www.vedcmalang.com Karyawan dilarang makan dan minum saat bekerja

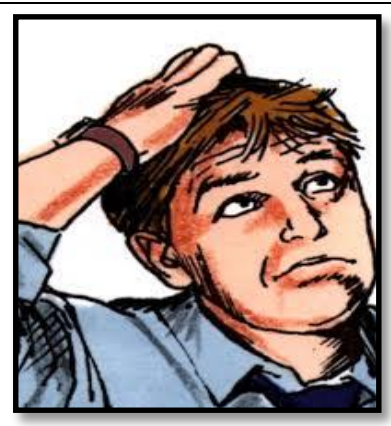

Sumber :

https://kepribadiankarakter.blogspot.co.id Hindari gerakan menggaruk kepala, tangan atau bagian tubuh lainnya saat bekerja, jika dilakukan maka segera mencuci tangan kembali

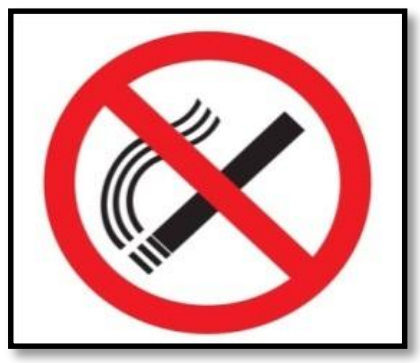

Sumber : http://www.vedcmalang.com Karyawan dilarang merokok saat bekerja

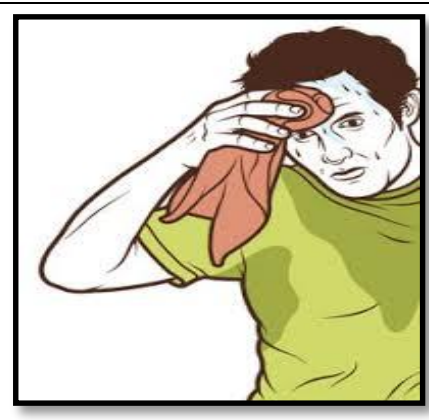

Sumber :

http://abdisr.blogspot.co.id

Karyawan wajib membersihkan keringat di badannya menggunakan handuk di luar tempat produksi 
Tabel 7. Standard Operating Procedure Kebersihan di Area Kerja

\begin{tabular}{cc}
\hline IKM TAHU SARI MURNI & Doc. No. \\
$01 / 01$
\end{tabular}

\section{TUJUAN}

Tujuan dari Standard Operating Procedure ini adalah mengolah kebersihan area produksi, sehingga menjamin keamanan dan kesehatan makanan serta lingkungan kerja.

\section{RUANG LINGKUP}

Prosedur ini berlaku untuk menjaga kebersihan area kerja sejak mulai bekerja sampai selesai bekerja dalam memproduksi tahu.

\section{DESKRIPSI PEKERJAAN}

Karyawan bertanggung jawab terhadap kebersihan area produksi, yang mencakup peralatan produksi, kebersihan lantai, dinding, ventilasi, langit-langit, toilet, pembuangan sampah, dan fasilitas perusahaan lainnya.

\section{RINCIAN LANGKAH}

1. Karyawan selalu membersihkan debu dan kotoran yang terdapat di lantai produksi menggunakan sapu ijuk dan pel sebelum proses produksi dimulai.

2. Karyawan selalu membersihkan lantai yang berlendir setelah proses pembuangan limbah cair menggunakan sapu lidi dan sikat lantai.

3. Karyawan membersihkan tempat cuci tangan yang terdapat di ruang produksi setiap hari dan dilengkapi dengan sabun cuci tangan yang tidak memiliki bau.

4. Karyawan membersihkan lantai toilet yang berada di ruang produksi setiap hari, untuk meningkatkan higiene, kenyamanan, dan mencegah timbulnya bau.

5. Karyawan setiap hari membuang sampah yang berada di area produksi ketika selesai proses produksi.

6. Karyawan membersihkan debu dan kotoran di dinding, jendela, ventilasi, dan langitlangit seminggu sekali menggunakan sapu ijuk.

7. Karyawan membersihkan saluran irigasi yang berada di lingkungan pabrik setiap hari menggunakan sapu lidi.

\begin{tabular}{ll}
\hline DISIAPKAN & DISAHKAN \\
\hline Tgl : 13/09/2017 & \\
Oleh : Riska Permana Sari & \\
\hline
\end{tabular}

\section{KESIMPULAN}

Berdasarkan evaluasi penilaian daftar periksa GMP-WISE terdapat enam kriteria yang menjadi prioritas perbaikan yaitu penyimpanan dan penanganan material/peralatan, desain tempat kerja, fasilitas kesejahteraan, organisasi pekerjaan, pengendalian proses produksi, dan program higiene dan sanitasi. Kriteria utama yang menjadi prioritas perbaikan proses produksi di IKM Tahu Sari Murni adalah program higiene dan sanitasi yang di dalamnya memiliki 3 sub kriteria yaitu program higiene karyawan, program higiene área kerja, dan antisipasi zat berbahaya. Kriteria tersebut memiliki bobot penilaian terbesar dibandingkan dengan kelima kriteria lainnya yaitu sebesar $22 \%$. Usulan perbaikan proses produksi di IKM Tahu Sari Murni yaitu berupa penyusunan peraturan rutin karyawan produksi dan penyusunan Standard Operating Procedure (SOP) kebersihan di area kerja. Penelitian ini dapat dilanjutkan mengenai pembuatan alat ukur keamanan pangan dengan menggabungkan kriteria GMP-WISE dan sertifikat jaminan halal.

\section{DAFTAR PUSTAKA}

BPOM. Peraturan Kepala Badan Pengawas Obat dan Makanan Republik Indonesia Tentang Cara Produksi Pangan yang Baik untuk Industri Rumah Tangga., Pub. L. No. HK.03.1.23.04.12.2206 (2012). Retrieved from

http://standarpangan.pom.go.id/dokumen/p eraturan/2012/Perka_BPOM_No_HK.03.1.2 3.04.12.2206_Tahun_2012_tentang_CPPB PIRT.pdf.

Damarasri, D. R., Partiwi, S. G., \& Gunawan, J. (2013). Penerapan Good Manufacturing Practice dan Work Improvement In Small Enterprise pada Usaha Kecil dan Menengah Untuk Pemenuhan Standar Kesehatan 
(Studi Kasus : UKM Tempe Tenggilis Mejoyo Surabaya). Institut Teknologi Sepuluh Nopember (ITS) Surabaya, 1-6. Retrieved from http://digilib.its.ac.id/public/lTS-paper33645-2509100002-paperpdf.pdf.

Fatmawati, S., Rosidi, A., \& Handarsari, E. (2013). Perilaku Higiene Pengolah Makanan Berdasarkan Pengetahuan Tentang Higiene Mengolah Makanan Dalam Penyelenggaraan Makanan di Pusat Pendidikan dan Latihan Olahraga Pelajar Jawa Tengah. Jurnal Pangan dan Gizi, 4(8), 45-52. Retrieved from https://jurnal.unimus.ac.id/index.php/jgizi/art icle/view/1032.

Fernando, R. (2014). Penerapan Life Cycle Assessment (LCA) pada Industri Tahu dengan Menggunakan Ketel UAP dan Bak Perebusan dalam proses Pemasakan (Studi Kasus di Sentra Pengrajin Tahu Mojosongo, Surakarta) (Universitas Gadjah Mada). Retrieved from http://etd.repository.ugm.ac.id/home/detail_ pencarian/77171.

Firdausi, F., Rahardjo, M., \& Hanani D, Y. (2017). Hubungan Kondisi Sanitasi dan Personal Higiene Pekerja Dengan Jumlah Angka Kuman pada Ikan Asap di Bandarharjo Kota Semarang. Jurnal Kesehatan Masyarakat (e-Journal), 5(5), 639-648. Retrieved from https://ejournal3.undip.ac.id/index.php/jkm/a rticle/view/19186.

Hanidah, I., Mulyono, A.T., Andoyo, R., Mardawati, E., \& Huda, S. (2018). Penerapan Good Manufacturing Practices Sebagai Upaya Peningkatan Kualitas Produk Olahan Pesisir Eretan-Indramayu. AGRICORE: Jurnal Agribisnis dan Sosial Ekonomi Pertanian, 3(1), 359-426. Retrieved from

http://jurnal.unpad.ac.id/agricore/article/view $/ 17585$.

International Labour Office (ILO). (2015). Pembinaan Peningkatan Keselamatan dan Kesehatan Kerja pada Usaha Kecil dan Menengah dengan Metode Pelatihan Partisipasi Aktif. Retrieved from https://wcd1.ilo.org/jakarta/whatwedo/public ations/WCMS_400187/lang--en/index.htm.

Ningsih, R. (2014). Penyuluhan Hygiene Sanitasi Makanan dan Minuman, Serta Kualitas Makanan yang Dijajakan Pedagang di Lingkungan SDN di Kota Samarinda. Jurnal Kesehatan Masyarakat, 10(1), 64-72. Retrieved from https://journal.unnes.ac.id/nju/index.php/ke mas/article/view/3071.

Putri, D. E. (2010). Strategi Pemasaran Tahu di Kota Surakarta. Universitas Sebelas Maret. Retrieved from https://digilib.uns.ac.id/dokumen/detail/1375 2/Strategi-pemasaran-tahu.

Sari, F.N. (2016). Penerapan Good Manufacturing Practices (GMP) di Dapur Rumah Sakit. Jurnal Kesehatan Lingkungan, 8(2), 248257.

https://ejournal.unair.ac.id/JKL/article/download/801 $8 / 4752$.

Setyawanti, O., \& Andayani, S.W. (2015). Higiene dan Sanitasi Jajan Pasar di Pasar Kotagede Yogyakarta. Jurnal Keluarga, 1(2), 130-137. Retrieved from https://jurnal.ustjogja.ac.id/index.php/keluar ga/article/view/612.

Suhardi, B., Kadita, M., \& Laksono, P. W. (2018). Perbaikan Proses Produksi dengan Standar Cara Produksi Pangan yang Baik (CPPB) dan Work Improvement in Small Enterprise (WISE) pada Industri Kerupuk Sala. Jurnal SIMETRIS, 9(1), 579-586. https://doi.org/https://doi.org/10.24176/simet .v9i1.2020

Suhardi, B., Putri, N. I., \& Astuti, R. D. (2019). Implementation of CPPB-IRT, WISE, and Halal Guarantee System on Bread Production. Jurnal Teknik Industri, 20(1), 22-33.

https://doi.org/10.22219/jtiumm.vol20.no1.2 2-33.

Suhardi, B., Wardani, S. V., \& Jauhari, W. A. (2019). Perbaikan Proses Produksi IKM XYZ Berdasarkan Kriteria CPPB-IRT, WISE, dan SJH LPPOM MUI. J@ti Undip : Jurnal Teknik Industri, 14(2), 93-102. https://doi.org/10.14710/jati.14.2.93-102.

Wardanu, A.P., \& Anhar, M. (2016). Penerapan Good Manufacturing Practice (GMP) pada Kelompok Usaha Bersama (KUB) Wide Mantolo Kecamatan Benua Kayong. Jurnal Teknologi Pangan, 7(1), 8-16. https://doi.org/10.35891/tp.v7i1.500.

Yulianto, A. \& Nurcholis. (2015). Penerapan Standard Hygienes dan Sanitasi Dalam Meningkatkan Kualitas Makanan di Food \& Beverage Department @ Hom Platinum Hotel Yogyakarta. Jurnal Khasanah IImu, 6(2), 31-39. Retrieved from https://ejournal.bsi.ac.id/ejurnal/index.php/k hasanah/article/view/484. 